Document downloaded from:

http://hdl.handle.net/10251/61922

This paper must be cited as:

Marín García, ML.; Zaragoza, RJ.; Miranda Alonso, MȦ.; Diaba, F.; Bonjoch, J. (2011).

Translocation versus cyclisation in radicals derived from $\mathrm{N}$-3-alkenyl trichloroacetamides. Organic and Biomolecular Chemistry. 9(9):3180-3187. doi:10.1039/c0ob01228a.

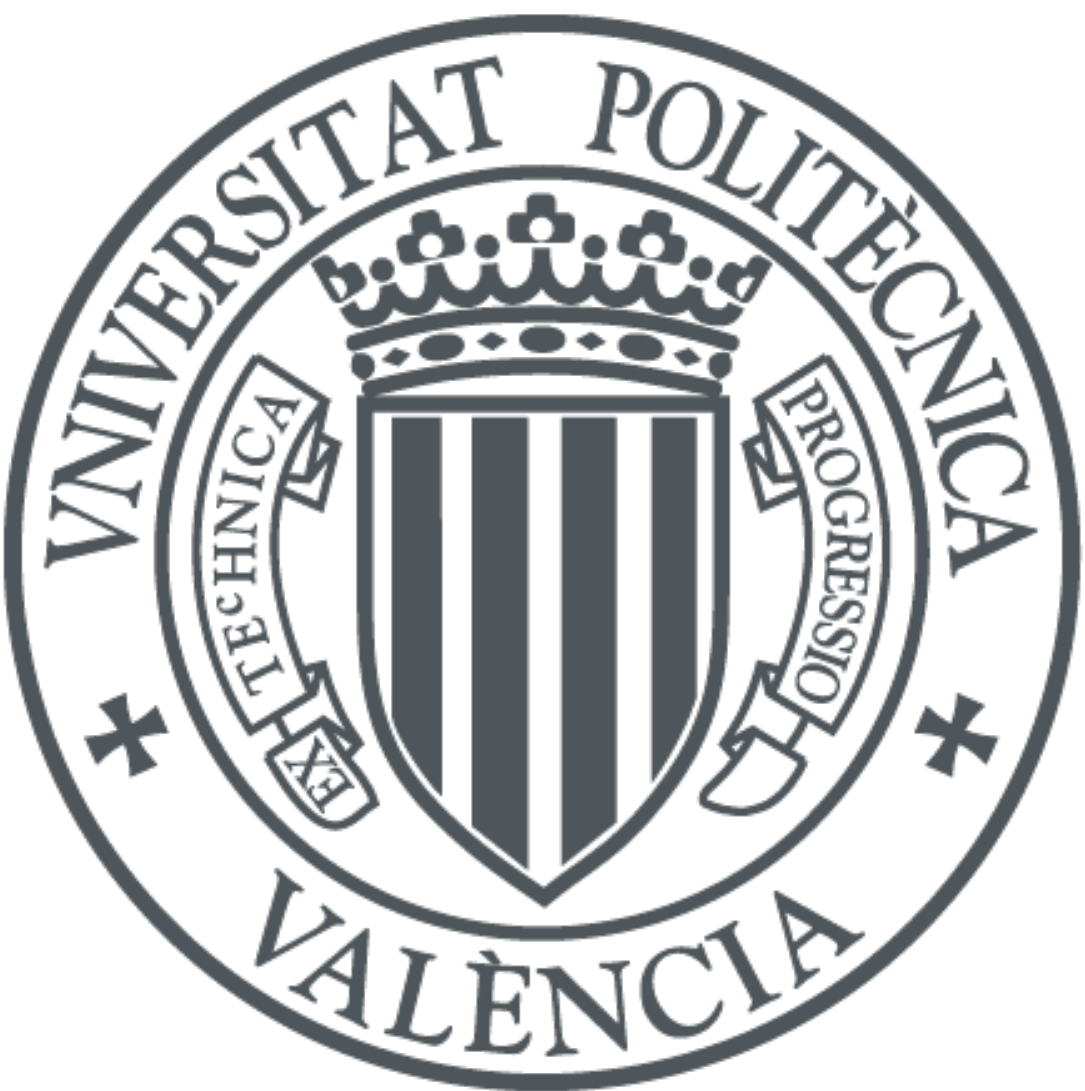

The final publication is available at

http://dx.doi.org/10.1039/c0ob01228a

Copyright Royal Society of Chemistry

Additional Information 


\title{
Translocation versus cyclisation in radicals derived from $N$-3-alkenyl trichloroacetamides $\uparrow$
}

\author{
M. Luisa Marin, ${ }^{* a}$ Ramon J. Zaragoza, ${ }^{* b}$ Miguel A. Miranda, ${ }^{a}$ Faïza Diaba ${ }^{c}$ and Josep Bonjoch ${ }^{c}$
}

Under radical reaction conditions, two different and competitive reaction pathways were observed from $N$-( $\alpha$-methylbenzyl)trichloro acetamides with a $N$-3-cyclohexenyl substituent: 1,4-hydrogen translocation and radical addition to a double bond. However, for radicals with an acyclic alkenyl side chain, the direct cyclisation process was exclusively observed. The dichotomy between translocation and 10 direct radical cyclisation in these substrates has been theoretically studied using density functional theory (DFT) methods at the B3LYP/6-31G** computational level.

\section{Introduction}

Trichloroacetamides have been used since the 1980 s as 15 radical precursors to synthesise nitrogen-containing heterocycles, such as $\beta-, \gamma$-, and $\delta$-lactams, in a variety of radical processes (e.g. atom transfer mediated by $\mathrm{CuCl}^{1}$ or Grubbs' ruthenium metathesis catalysts, ${ }^{2}$ and the hydride reductive method $^{3}$ ). Their usefulness in radical cyclisations 20 leading to 6-membered rings can be attributed to the stability of the formed $\mathrm{N}$-(3alkenyl)carbamoyldichloromethyl radicals, which reduces the occurrence of the disruptive 1,5-hydrogen shift. ${ }^{4}$ Several years ago, we showed that $N$-benzyl- $N$-cyclohexenyl 25 trichloroacetamides $\mathbf{1}$ are versatile reagents for the synthesis of 2-azabicyclo[3.3.1]nonanes 2 (Scheme 1), via radical cyclisation.

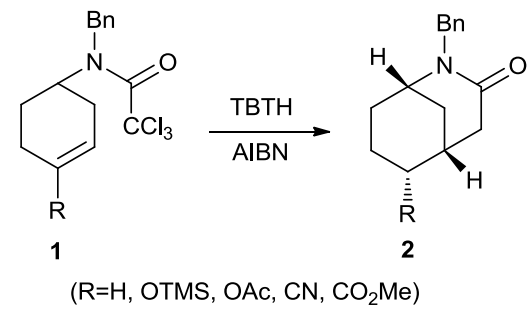

Scheme 1 Synthesis of 2-azabicyclo[3.3.1]nonanes.

30 Attempts to extend this morphan approach to the synthesis of enantiopure compounds with a (S)-1phenylethyl group at the nitrogen produced a surprising result when using either electron-rich ${ }^{6}$ or electron-poor ${ }^{7}$ radical acceptors (Scheme 2). Together with the expected 2-

35 azabicyclo[3.3.1]nonanes $\mathbf{4}$, the normorphans $\mathbf{5}$ were also

${ }^{a}$ Instituto de Tecnología Química-Departamento de Química (UPVCSIC), Avda de los Naranjos s/n, E-46022, Valencia, Spain. E-mail: marmarin@qim.upv.es; Fax: +34963877809; Tel: +34963877815.

$40{ }^{b}$ Departamento de Quimica Organica, Universidad de Valencia, Dr. Moliner 50, 46100 Burjassot, Valencia, Spain. E-

mail:ramon.j.zaragoza@uv.es

${ }^{c}$ Laboratori de Química Orgànica, Facultat de Farmàcia, Institut de Biomedicina (IBUB),Universitat de Barcelona, Av. Joan XXIII $s / n$, 45 08028-Barcelona, Spain.

$\dagger$ Electronic Supplementary Information (ESI) available: . See DOI: $10.1039 / \mathrm{b} 000000 \mathrm{x} /$ isolated. The former are the result of 6-exo-trig radical cyclisation, whereas the latter arise from a competitive 50 process involving 1,4-hydrogen transfer, ${ }^{8}$ followed by 5 exo-trig cyclisation with configurational inversion at the stereogenic benzylic carbon.<smiles>[R]C1=CC[C@H](N(C(=O)C(Cl)(Cl)Cl)[C@@H](C)c2ccccc2)[C@H](C)CC1</smiles>

3a (R=OTMS)

3b $(\mathrm{R}=\mathrm{CN})$<smiles>[R]C1=CC[C@H](N(C(=O)C(Cl)(Cl)Cl)[C@@H](C)c2ccccc2)CC1</smiles>

3c $(\mathrm{R}=\mathrm{OTMS})$ 3d $(\mathrm{R}=\mathrm{CN})$
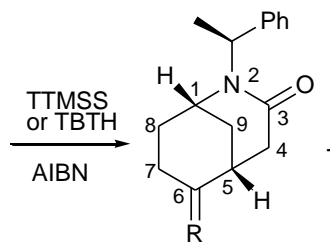

$4 a(20 \%)$ 4b $(44 \%) \quad(\mathrm{R}=\alpha-\mathrm{CN}, \beta-\mathrm{H}), 5 \mathrm{~b}(20 \%)$

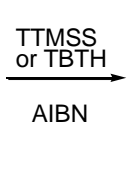<smiles>[R]C1=CC[C@H]2C[C@H]1CC(=O)N2[C@@H](C)c1ccccc1</smiles>
$4 c(42 \%)$ $\mathbf{4 d}(28 \%) \quad(\mathrm{R}=\alpha-\mathrm{CN}, \beta-\mathrm{H}) \quad \mathbf{5 d}(39 \%)$

55 Scheme 2 Synthesis of 2-azabicyclo[3.3.1]nonanes (4) together with normorphans (5) from electron-rich (3a and $\mathbf{3 c}$ ) or electron-poor (3b and 3d) $N$-cyclohexenyl trichloroacetamides.

At this point, we decided to explore the scope of this unprecedented radical rearrangement occurring in the tin60 hydride-promoted cyclisation of trichloroacetamides bearing a $N$-(1-phenylethyl) substituent. ${ }^{9} \quad$ To assess whether translocation is a particular process in the synthesis of morphans or it can also occur when other alkylbenzyl moieties are present, simple open-chain trichloroacetamides

$65(6,7$, and 9) were prepared, and their behaviour under radical reaction conditions (the hydride method) was examined.

To obtain further insight into these radical processes leading to mono- and bicyclic compounds, theoretical 70 studies on their reaction pathways were also carried out. Thus, the reductive cyclisation of trichloroacetamides $\mathbf{7}, \mathbf{3 b}$, $1(\mathrm{R}=\mathrm{CN})$ and $\mathbf{3 d}$ has been studied by means of DFT 
calculations. Based on the theoretical data obtained, different reaction mechanisms are proposed to explain the experimental results.

\section{Results and discussion}

\section{${ }_{5}$ Synthetic studies}

Preparation of the starting materials $\mathbf{6}$ and $\mathbf{7}$ from the corresponding amines in the trichloroacetylation step was improved upon the previously reported procedure. ${ }^{10}$ The unreported trichloracetamide $\mathbf{9}$ was prepared from $\mathbf{7}$ by 10 ozonolysis to give aldehyde $\mathbf{8}$, followed by treatment with isopropenyl acetate. ${ }^{11}$ The enol acetate $\mathbf{9}$ was obtained as a mixture of $\mathrm{Z} / \mathrm{E}$ isomers (4:6 ratio) (Scheme 3). When trichloroacetamides $\mathbf{6}, \mathbf{7}$ and $\mathbf{9}$ were treated with tris(trimethylsilyl)silane (TTMSS)/AIBN, pyrrolidone $\mathbf{1 0}$

$15(80 \%)$ and piperidones $\mathbf{1 1}(53 \%)$ and $\mathbf{1 2}$ (78\%) were, respectively, formed. The isolated compounds are the result of cyclisation of the 1-(carbamoyl)dichloromethyl radical onto the double bond without any diastereoselectivity (epimeric 1:1 mixtures were obtained in every case). The 20 1,4-translocation products were not detected for these openchain trichloroacetamides that contain the alkylbenzyl moiety but lack the cyclohexene. Therefore, it seems that both structural features are required to observe the translocation proccess.

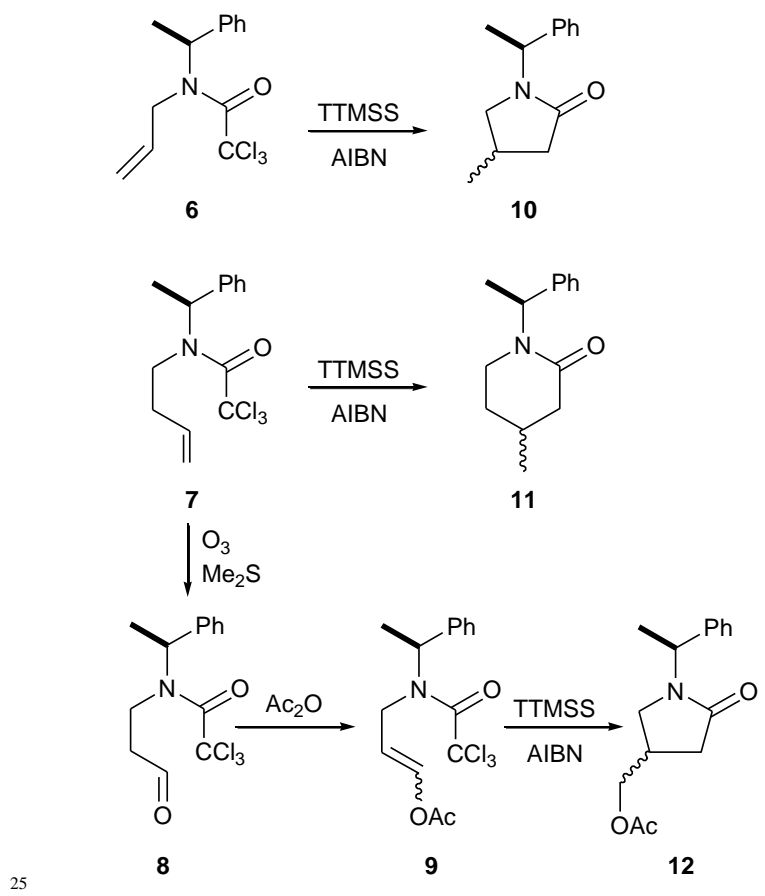

Scheme 3 Cyclisation of trichloroacetamides 6, 7 and 9.

\section{Theoretical DFT studies}

\section{i) Conversion of 7 into 11 and 11a}

30 The suggested mechanism is depicted in Scheme 4; the energies of the relevant species are shown in Fig. 1 and Table 1; finally, geometries of the involved transition states are shown in Fig. 2.
For the conversion of $\mathbf{7}$ into $\mathbf{1 1}$ or $\mathbf{1 1 a}$ (not observed) two 35 possible reaction paths (paths 1 and 2 in Scheme 4) have been investigated. In this mechanism, radical cyclisation or hydrogen translocation from the initially generated 1(carbamoyl)dichloromethyl radical are assumed to be faster than hydrogen abstraction, as experimentally evidenced in 40 the morphan series. ${ }^{7}$ In path 1 , the initial intermediate R-1 undergoes an intramolecular attack of the dichloromethyl radical onto the olefinic carbon with simultaneous sixmembered ring formation, through TS1, to give cyclic radical $\mathbf{R - 2}$. Final reduction of the radical intermediate $\mathbf{R - 2}$ 45 leads to the diastereomeric mixture of methylpiperidones 11. It is worth noting that the possibility for the radical $\mathbf{R - 1}$ to attack the olefin by its $r e$-face and $s i$-face results in two transition states TS1-re and TS1-si, respectively.

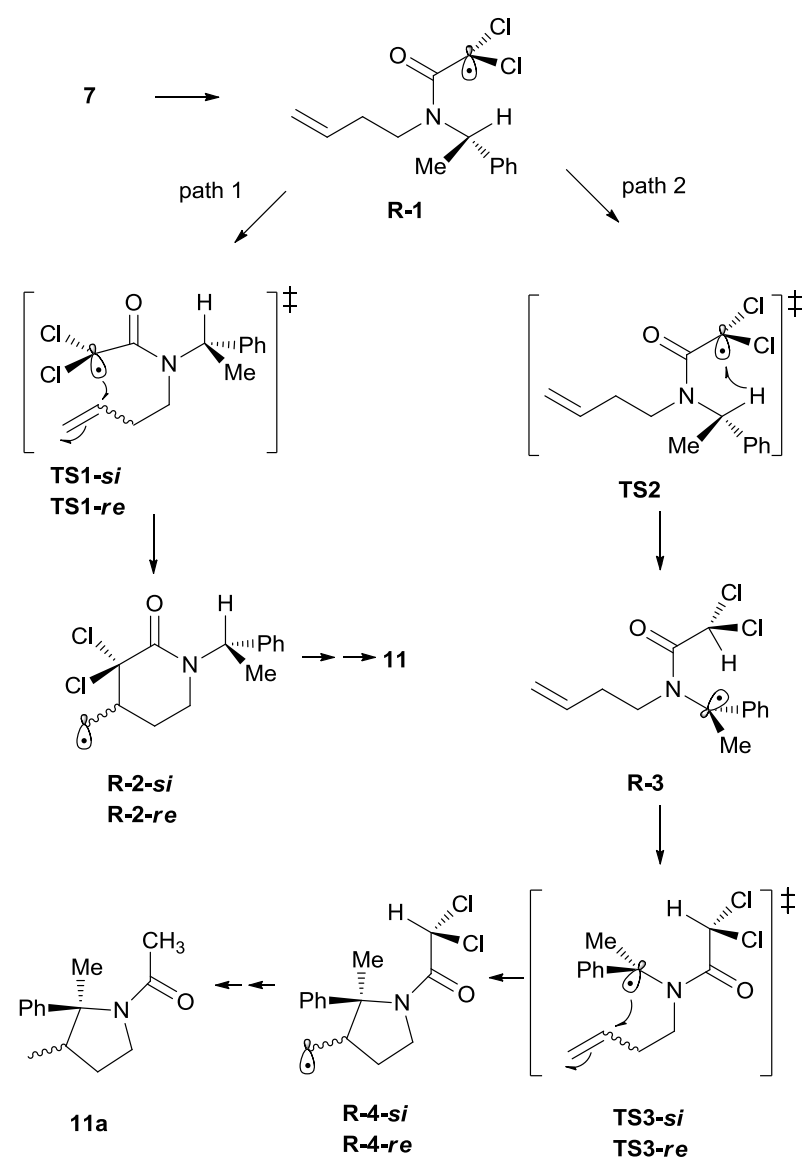

Scheme 4 Suggested mechanism for the conversion of $\mathbf{7}$ into $\mathbf{1 1}$ and $11 a$.

In the reaction path $2, \mathbf{R}-\mathbf{1}$ suffers an intramolecular 55 hydrogen transfer from the benzylic position to the dichloromethyl group, through TS2, leading to benzyl radical $\mathbf{R - 3}$, which is stabilised by conjugation with the aromatic ring. Intramolecular attack of $\mathbf{R - 3}$ to the olefinic carbon with simultaneous five-membered ring formation 60 through TS3 gives rise to R-4. Subsequent reduction would afford the epimeric mixture of methylpyrrolidines 11a. As mentioned above for path 1, both TS3-re and TS3-si may 
result from the radical attack on both faces of the olefin, giving rise to radicals $\mathbf{R}-\mathbf{4}-r \boldsymbol{e}$ and $\mathbf{R}-\mathbf{4}-\mathbf{s i}$, respectively.

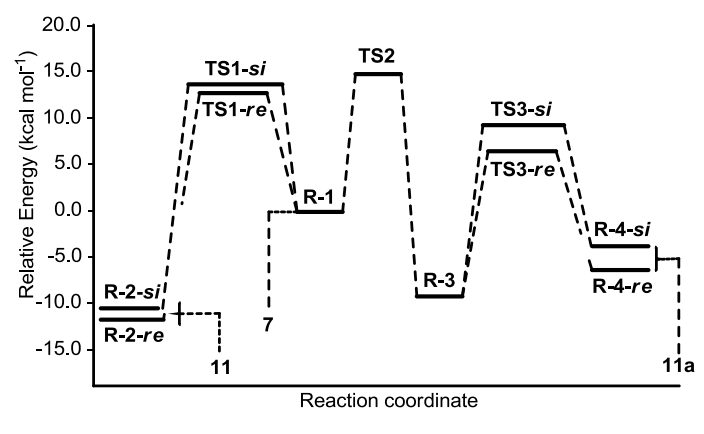

Fig. 1 B3LYP/6-31G** Energy profiles for the radical transformations leading from $\mathbf{7}$ to $\mathbf{1 1}$ and 11a in benzene; 7, 11 and 11a are off the scale.

The conversion of dichloromethyl radical R-1 into the 10 piperidine radical R-2-re has an energy barrier of $12.8 \mathrm{kcal}$ $\mathrm{mol}^{-1}$ (TS1-re), while the energy barrier for the transformation into piperidone radical R-2-si is $13.4 \mathrm{kcal}$ mol $^{-1}$ (TS1-si) (see Fig. 1 and Table 1). These energy values indicate that the attack of radical R-1 on the re-face of the 15 olefin is, from the kinetic point of view, slightly favoured. However, this energy difference still allows the competition between both pathways in agreement with the observed experimental results. Overall, the conversion of $\mathbf{R}-\mathbf{1}$ into $\mathbf{R}-$ 2-re and R-2-si is thermodynamically favoured by 11.9 and $2010.7 \mathrm{kcal} \mathrm{mol}^{-1}$, respectively.

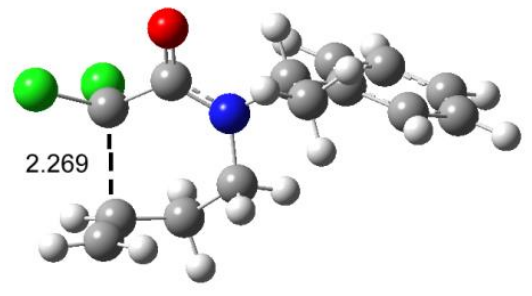

TS1-si

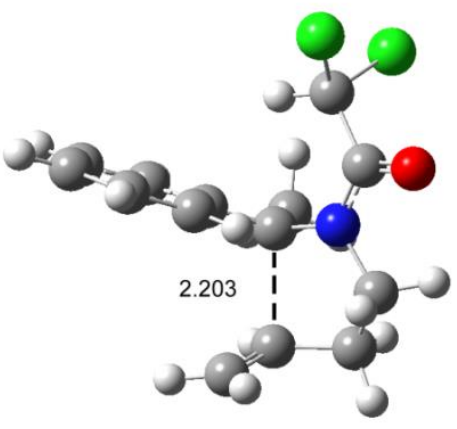

TS3-si

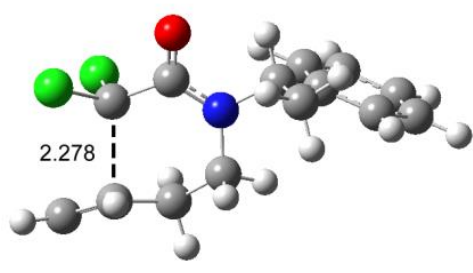

TS1-re

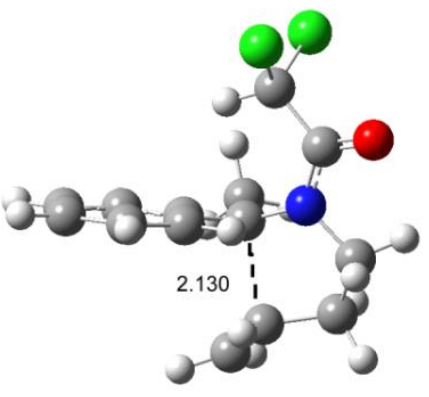

TS3-re
Table 1 Total $\left(E\right.$, au) and relative energies $\left(\Delta E, \mathrm{kcal} \mathrm{mol}^{-1}\right)$, at B3LYP/6-31G** level in benzene, of the stationary points for the radical transformations of 7 leading to $\mathbf{1 1}$ and 11a.

\begin{tabular}{ccc} 
& $E$ & $\Delta E$ \\
\hline R-1 & -1593.447221 & 0.0 \\
TS1-si & -1593.425862 & 13.4 \\
TS1-re & -1593.426832 & 12.8 \\
R-2-si & -1593.464250 & -10.7 \\
R-2-re & -1593.466231 & -11.9 \\
TS2 & -1593.424075 & 14.5 \\
R-3 & -1593.462295 & -9.5 \\
TS3-si & -1593.432970 & 8.9 \\
TS3-re & -1593.437124 & 6.3 \\
R-4-si & -1593.453740 & -4.1 \\
R-4-re & -1593.457743 & -6.6
\end{tabular}

${ }_{25}$ On the other hand, the conversion of radical R-1 into the pyrrolidine radical R-4 (path 2, Scheme 4) has an energy barrier of $14.5 \mathrm{kcal} \mathrm{mol}^{-1}$ (TS2). Initial hydrogen transfer is the rate determining step of the process (TS2), being more energetic than the subsequent intramolecular attack of the 30 benzyl radical to the $r e$-face or $s i$-face of the olefin (TS3-re and TS3-si, 6.3 and $8.9 \mathrm{kcal} \mathrm{mol}^{-1}$, respectively). Hence, TS2 (path 2) is 1.7 and $1.1 \mathrm{kcal} \mathrm{mol}^{-1}$, respectively, above TS1-re and TS1-si (path 1). As a consequence, the methylpyrrolidines 11a should be minor products in the 35 reaction mixture (ca. $3 \%$ ), and may or may not be observed. 


\section{ii) Conversion of $3 b$ into $4 b$ and $5 b$}

The mechanism proposed for the transformation of $\mathbf{3 b}$ into $\mathbf{4 b}$ and $\mathbf{5 b}$ (Scheme 5) is based on a theoretical treatment analogous to that described above for the conversion of $\mathbf{7}$ into $\mathbf{1 1}$ and 11a. 5 The energies of the relevant species are shown in Fig. 3 and Table 2; Fig. 4 shows the geometries of the transition states involved in the proposed mechanism.

In this case, the starting point is the most stable conformer of dichloromethyl radical $\mathbf{R - 5}$, bearing the acetamide moiety 10 at the equatorial position, that can evolve through paths 1 or 2. Along the former R-5 is first converted into its conformer R-5a by rotation of the $\mathrm{N}-\mathrm{CO}$ bond through transition state TS4. Then, R-5a changes to the inverted-chair conformation $\mathbf{R}-5 \mathbf{b}$, through TS5, in order to make the subsequent attack to 15 the double bond (by TS6) feasible. It is worth noting that inversion of the chair conformation prior to the N-CO bond rotation, results in a higher energetic barrier. Reduction of the intermediate R-6 leads to azabicyclononane $\mathbf{4 b}$. The radical attack is only possible from the same side of the molecule, 20 due to the conformational restrictions of TS6, giving rise to only one diastereoisomer of $\mathbf{4 b}$.

In path 2, radical R-5 undergoes an intramolecular hydrogen transfer from the benzylic position to the dichloromethyl group through transition state TS7. The 25 stabilised benzyl radical intermediate R-7 suffers a conformational change of the cyclohexene ring to an invertedchair, with simultaneous rotation of the $\mathrm{C} 1-\mathrm{N}$ bond (through TS8), leading to radical R-7a. Finally, R-7a undergoes an intramolecular radical addition at the olefinic carbon with 30 simultaneous five-membered ring-formation (through TS9), giving rise to $\mathbf{R - 8}$. Eventually, reduction of this radical affords normorphan $\mathbf{5 b}$.

Thus, dichloromethyl radical R-5 is converted into R-6 through three transition states TS4, TS5 and TS6 with relative 35 energy values of $11.6,13.2$ and $13.1 \mathrm{kcal} \mathrm{mol}^{-1}$, respectively (see Fig. 3 and Table 2). As TS5 and TS6 have similar energetic levels, they are the rate limiting steps. The dichloromethyl radical $\mathbf{R - 5}$, stabilised by interaction with the benzylic hydrogen, is converted into the less stabilised radical $40 \mathbf{R}-5 \mathbf{a}\left(+3.9 \mathrm{kcal} \mathrm{mol}^{-1}\right)$. Subsequent conversion of R-5a into $\mathbf{R - 5 b}$ is clearly a disfavoured step from the energetic point of view (+5.6 kcal mol${ }^{-1}$ ). Remarkably, formation of R-6 from $\mathbf{R - 5 b}$ is thermodynamically favoured. On the other hand, the transformation of R-5 into R-8 has an energetic barrier of $4514.1 \mathrm{kcal} \mathrm{mol}^{-1}$ (TS7) that corresponds to the initial hydrogen transfer. This step is more energetic than the subsequent conformational change $\left(\right.$ TS8 $=1.1 \mathrm{kcal} \mathrm{mol}^{-1}$ ) and than the intramolecular attack of the benzyl radical at the olefinic carbon $\left(\right.$ TS9 $\left.=8.5 \mathrm{kcal} \mathrm{mol}^{-1}\right)$. The transformation of $\mathbf{R - 5}$ into ${ }_{50} \mathbf{R}-7$ is exothermic $\left(-8.3 \mathrm{kcal} \mathrm{mol}^{-1}\right)$ due to stabilisation of the benzyl radical formed. The conformational change from R-7 to $\mathbf{R}-7 \mathbf{a}$ is again an endothermic step $\left(+4.0 \mathrm{kcal} \mathrm{mol}^{-1}\right)$; however, the radical attack on the double bond giving rise to the bycyclic radical $\mathbf{R - 8}$ is exothermic $\left(-5.6 \mathrm{kcal} \mathrm{mol}^{-1}\right)$.

55 Overall, both proposed pathways are exothermic by -17.0 $\mathrm{kcal} \mathrm{mol}^{-1}$ and $-9.9 \mathrm{kcal} \mathrm{mol}^{-1}$, respectively. When the energetic barriers of both pathways are compared, TS5/TS6 for path 1 and TS7 for path 2, the former is $0.9 \mathrm{kcal} \mathrm{mol}^{-1}$ lower. This small difference allows competition between the 60 two pathways, with formation of azabicyclononane $\mathbf{4 b}$ being slightly favoured over that of normorphane $\mathbf{5 b}$, in agreement with the experimentally observed results.

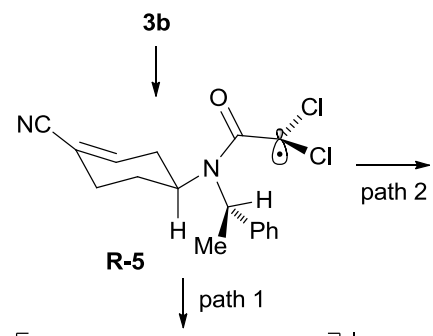

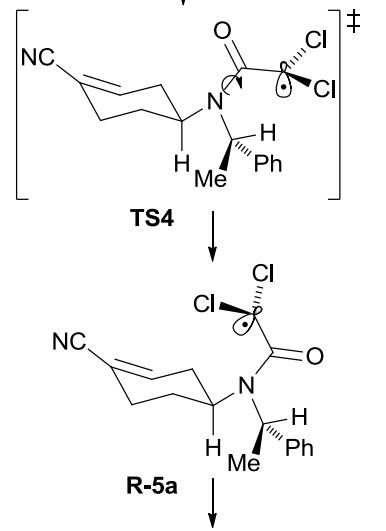

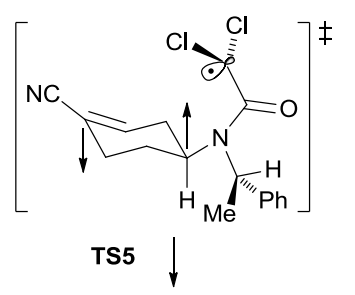

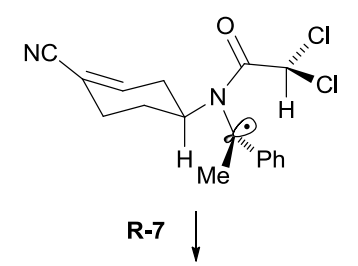

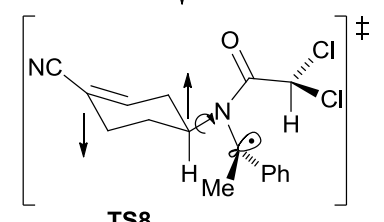

TS8

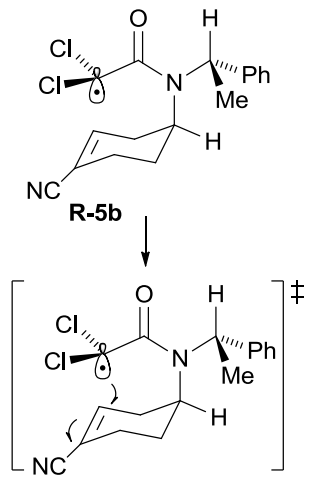

TS6

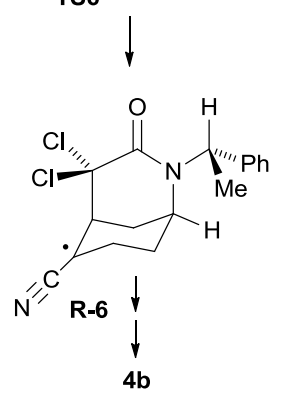<smiles>[Al-]I</smiles>

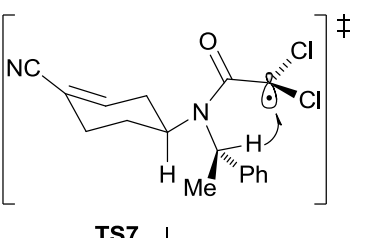<smiles>C1CCCCC1</smiles><smiles>[3H][3H]</smiles>

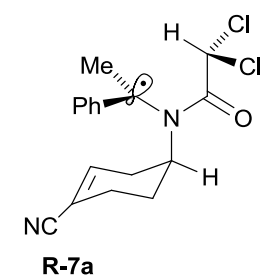<smiles>CC(CC1CCCCC1)N(C(=O)C(Cl)Cl)C1CCCC(C#N)C1</smiles>

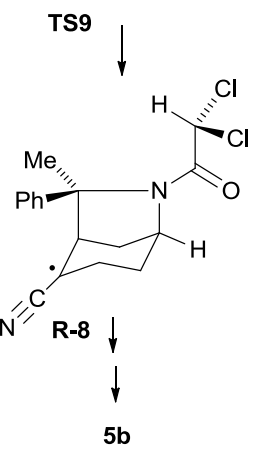

Scheme 5 Suggested mechanism for the conversion of $\mathbf{3 b}$ into $\mathbf{4 b}$ and $\mathbf{5 b}$. 


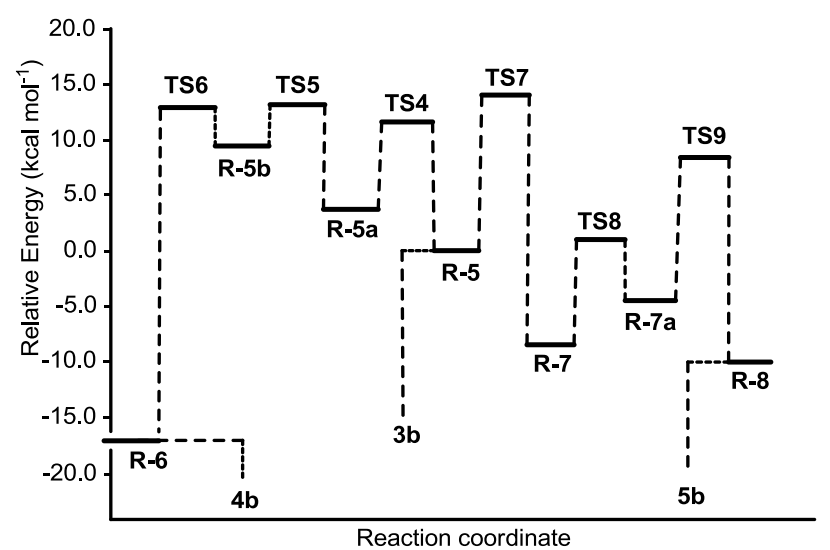

Fig. 3 B3LYP/6-31G** Energy profiles for the radical transformations of $\mathbf{3 b}$ leading to $\mathbf{4 b}$ and $\mathbf{5 b}$ in benzene; $\mathbf{3 b}, \mathbf{4 b}$ and $\mathbf{5 b}$ are off the scale.
Table 2 Total $(E, \mathrm{au})$ and relative energies $\left(\Delta E, \mathrm{kcal} \mathrm{mol}^{-1}\right)$, at B3LYP/6$31 \mathrm{G}^{* *}$ level in benzene, of the stationary points for the radical transformations of $\mathbf{3 b}$ into $\mathbf{4 b}$ and $\mathbf{5 b}$.

\begin{tabular}{lcc} 
& $E$ & $\Delta E$ \\
\hline R-5 & -1763.124648 & 0.00 \\
TS4 & -1763.106144 & 11.6 \\
R-5a & -1763.118500 & 3.9 \\
TS5 & -1763.103677 & 13.2 \\
R-5b & -1763.109453 & 9.5 \\
TS6 & -1763.103828 & 13.1 \\
R-6 & -1763.151660 & -17.0 \\
TS7 & -1763.102159 & 14.1 \\
R-7 & -1763.137806 & -8.3 \\
TS8 & -1763.122957 & 1.1 \\
R-7a & -1763.131537 & -4.3 \\
TS9 & -1763.111040 & 8.5 \\
R-8 & -1763.140392 & -9.9
\end{tabular}

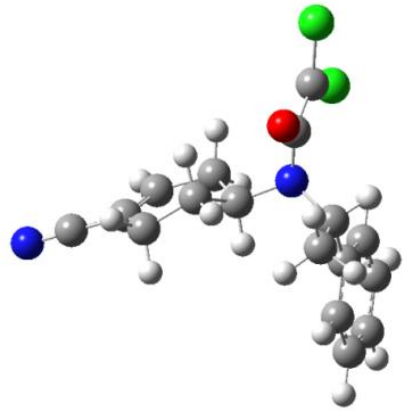

TS4

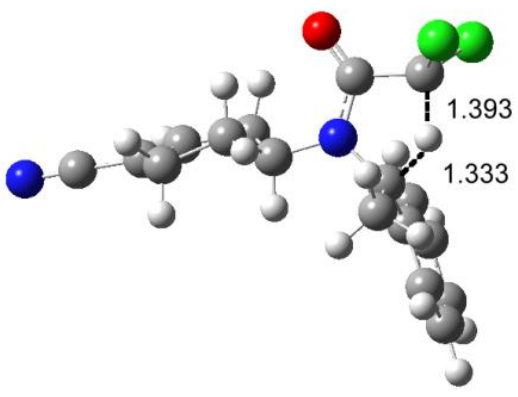

TS7

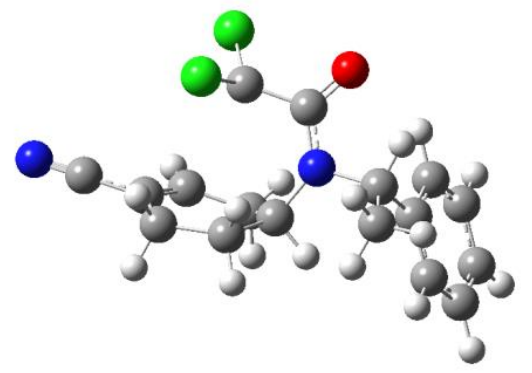

TS5

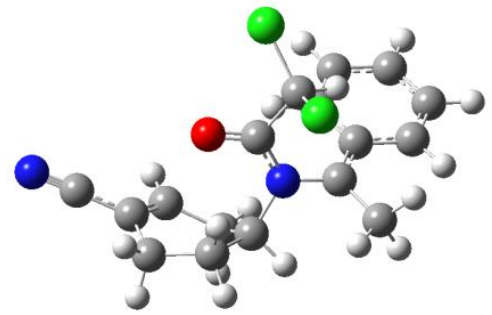

TS8

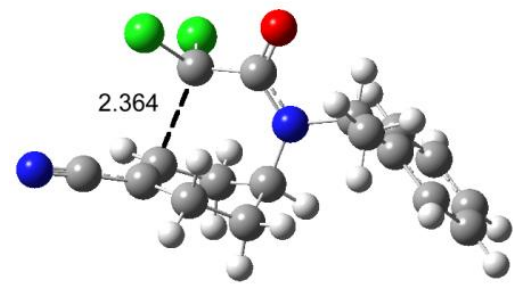

TS6

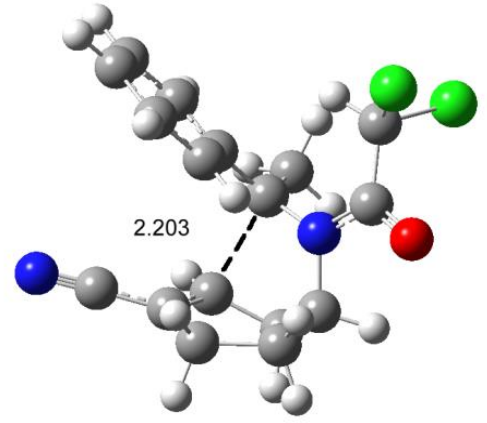

TS9

Fig. 4 Transition structures corresponding to the conversion of $\mathbf{3 b}$ into $\mathbf{4 b}$ and $\mathbf{5 b}$. Bond length values are given in $\AA$.

\section{iii) Conversion of $3 d$ and 1 into $4 d / 5 d$ and $2 / 2 a$}

${ }_{15}$ From the above theoretical calculations, the rate limiting steps for the conversion of $\mathbf{3 b}$ into $\mathbf{4 b / 5 b}$ are TS5/TS6 and TS7, respectively. Hence, to simplify the theoretical study for the conversion of $\mathbf{3 d}$ into $\mathbf{4 d} / \mathbf{5 d}$ and $\mathbf{1}$ into $\mathbf{2} / \mathbf{2} \mathbf{a}$ only those transition states have been considered (for clarity compound ${ }_{20} \mathbf{3 d}$ has been depicted as its enantiomer, see Scheme 6). The energies of the relevant species are shown in Table 3; Fig. 5 shows the geometries of the involved transition states.

Here, R-9 is the initially formed radical in the transformation of $\mathbf{3 d}$ into $\mathbf{4 d}$ or $\mathbf{5 d}$. Transition states TS10 and ${ }_{25}$ TS11 correspond to the energetic barriers for the conformational change for chair inversion and intramolecular radical attack to the olefinic carbon, respectively, along path 1. Likewise, TS12 is the barrier for the translocation of the 
benzylic hydrogen to the dichloromethyl moiety leading to $\mathbf{5 d}$ along path 2 . The equivalent species for the transformation of trichloroacetamide $\mathbf{1}$ into the azabicyclononane $\mathbf{2}$ or normorphane 2a (not experimentally observed) are R-9a, 5 TS10a, TS11a and TS12a.

The energetic barriers for the conversion of $\mathbf{3 d}$ into $\mathbf{4 d} / \mathbf{5 d}$ are similar to the ones calculated above for the epimer $\mathbf{3 b}$ (see Table 3). Again, TS10 and TS11 (path 1) have very similar values (13.8 kcal mol${ }^{-1}$ and $13.2 \mathrm{kcal} \mathrm{mol}^{-1}$, respectively) 10 while TS12 (path 2) is higher in energy (14.5 kcal mol ${ }^{-1}$ ). When the energetic barriers for the two pathways are compared, TS10 for path 1 and TS12 for path 2, the former is $0.7 \mathrm{kcal} \mathrm{mol}^{-1}$ lower. This difference is slightly smaller than that observed for the isomer $\mathbf{3 b}\left(0.9 \mathrm{kcal} \mathrm{mol}^{-1}\right)$ and supports 15 the experimentally observed trend of increased translocation product $\mathbf{5 d}$.

Finally the theoretical calculations are significantly different for trichloroacetamide $\mathbf{1}$ that contains a benzyl instead of a 1-phenylethyl group. The energies of the implied 20 transition states in path 1 for conversion of 1 into 2 (TS10a and TS11a) are lower (13.0 kcal mol ${ }^{-1}$ and $10.9 \mathrm{kcal} \mathrm{mol}^{-1}$, respectively) than in the case of TS10 and TS11. On the other hand TS12a (the energetic barrier for the conversion of $\mathbf{1}$ into 2a through path 2) is now $16.1 \mathrm{kcal} \mathrm{mol}^{-1}$, much higher than ${ }_{25}$ TS12 (14.5 kcal mol${ }^{-1}$ ). This is reasonable, in view of the lower stability of secondary versus tertiary benzylic radicals. As a conclusion, the energy barrier for conversion of $\mathbf{1}$ into $\mathbf{2}$ through path 1 is now clearly lower by $3.1 \mathrm{kcal} \mathrm{mol}^{-1}$ than for conversion of $\mathbf{1}$ into $\mathbf{2 a}$ through path 2 . These calculations are 30 in complete agreement with the experimental results, and explain why normorphane $\mathbf{2 a}$ was not observed.

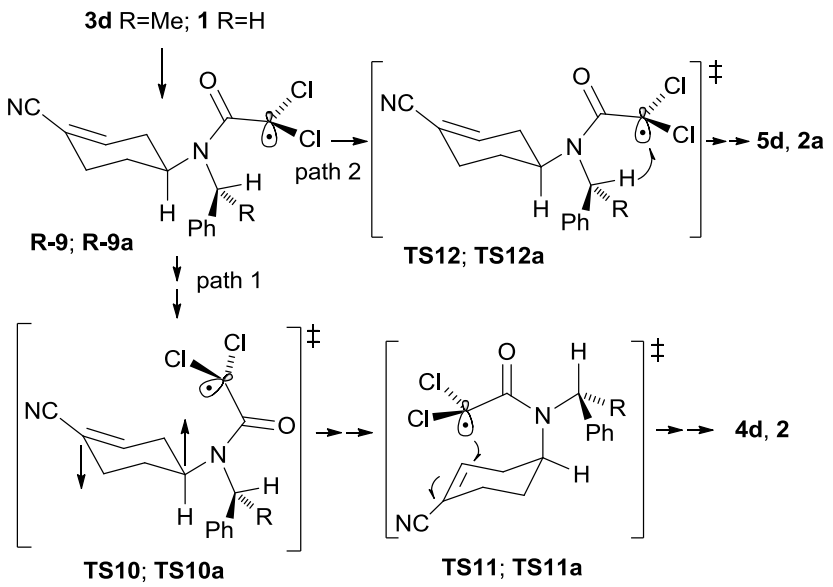

35 Scheme 6 Simplified mechanism for the conversion of $\mathbf{3 d}$ and $\mathbf{1}$ into $\mathbf{4 d} / \mathbf{5} \mathbf{d}$ and $2 / 2 \mathbf{a}$.

Table 3 Total $(E$, au $)$ and relative energies $\left(\Delta E, \mathrm{kcal} \mathrm{mol}^{-1}\right)$, at B3LYP/6$31 \mathrm{G}^{* *}$ level in benzene, of the most relevant transition states for the radical transformations of $\mathbf{3 d}$ and $\mathbf{1}$ into $\mathbf{4 d} / \mathbf{5 d}$ and $\mathbf{2 / 2} \mathbf{a}$.

\begin{tabular}{lcc} 
& \multicolumn{1}{c}{$E$} & $\Delta E$ \\
\hline R-9 & -1763.117817 & 0.0 \\
TS10 & -1763.095888 & 13.8 \\
TS11 & -1763.096831 & 13.2 \\
TS12 & -1763.094658 & 14.5 \\
& & \\
T9a & -1723.802658 & 0.0 \\
TS10a & -1723.781910 & 13.0 \\
TS11a & -1763.785349 & 10.9 \\
TS12a & -1763.777087 & 16.1
\end{tabular}

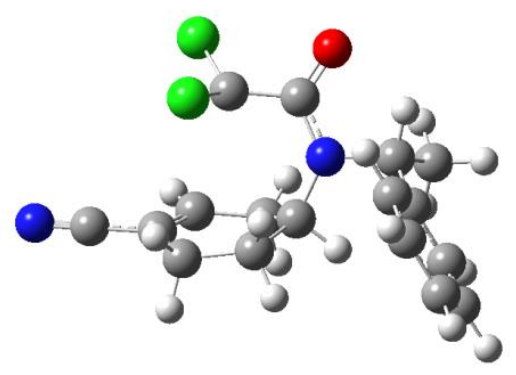

TS10

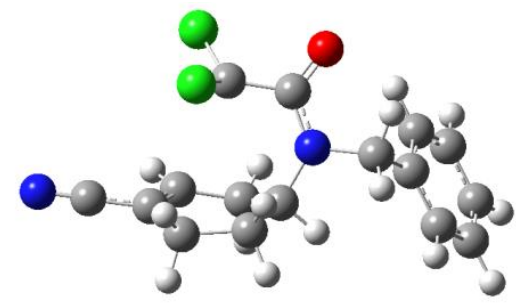

TS10a

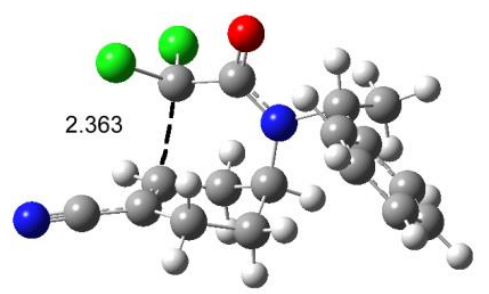

TS11

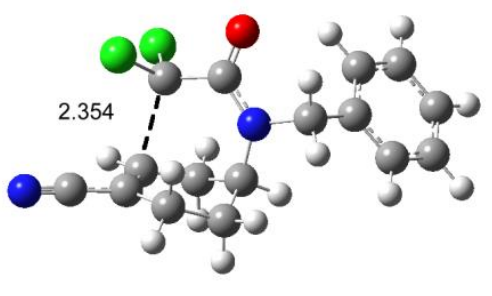

TS11a

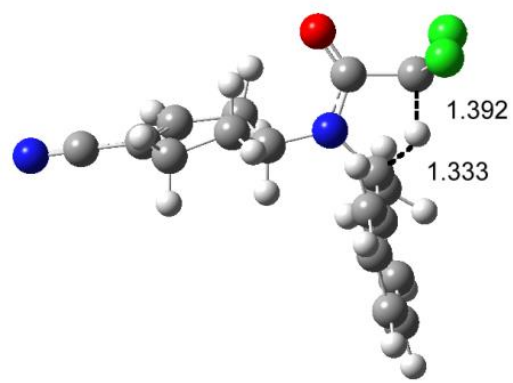

TS12

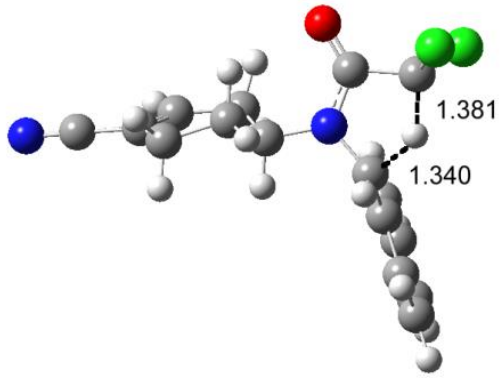

TS12a

Fig. 5 Transition structures corresponding to the conversion of $\mathbf{3 d}$ and $\mathbf{1}$ into $\mathbf{4 d / 5 d}$ and $\mathbf{2} / \mathbf{2} \mathbf{a}$. Bond length values are given in $\AA$. 


\section{Summary and conclusions}

The radical cyclisation of $N$-cyclohexenyl trichloroacetamides using AIBN/TTMSS gives rise to 2-azabicyclo[3.3.1]nonanes 5 with good overall yields. However, when $N$-cyclohexenyl- $N$ (1-phenylethyl) trichloroacetamides are submitted to similar conditions, normorphane derivatives are also isolated. The former are the result of the expected 6-exo-trig radical cyclisation, whereas the latter come from a competitive 10 process involving a 1,4-hydrogen transfer, followed by a 5exo-trig cyclisation. When the same experimental conditions were applied to trichloroacetamides bearing an $\mathrm{N}$-(1phenylethyl) substituent and a simple open-chain alkenyl moiety, the obtained products result only from the cyclisation

15 of the 1-(carbamoyl)dichloromethyl radical onto the double bond. The 1,4-translocation products are not detected. Therefore, it seems that the two structural features are required for the translocation to occur, namely the alkyl benzyl moiety and the cyclohexene ring.

20 Theoretical DFT calculations have been performed to explain the formation of products resulting from cyclisation of the 1-(carbamoyl)dichloromethyl radical onto the double bond (path 1) and/or the products arising from translocation of the benzylic hydrogen to the dichloromethyl moiety followed by a 25 cyclisation (path 2). The relative energy barriers for the involved processes are in good agreement with the experimental results.

\section{Experimental Section}

\section{General}

30 All reactions were carried out under an argon atmosphere with dry, freshly distilled solvents under anhydrous conditions. Analytical thin-layer chromatography was performed on $\mathrm{SiO}_{2}$ (Merck silica gel $60 \mathrm{~F}_{254}$ ), and the spots were located with $1 \%$ aqueous $\mathrm{KMnO}_{4}$ or $2 \%$ ethanolic anisaldehyde. ${ }_{35}$ Chromatography refers to flash chromatography and was carried out on $\mathrm{SiO}_{2}$ (SDS silica gel 60 ACC, 35-75 $\mu \mathrm{m}, 230$ 240 mesh ASTM). Drying of organic extracts during workup of reactions was performed over anhydrous $\mathrm{MgSO}_{4}$ except where stated otherwise. NMR spectra were recorded in $\mathrm{CDCl}_{3}$ 40 on a Varian Gemini 300 or Varian VNMRS 400. Chemical shifts of ${ }^{1} \mathrm{H}$ and ${ }^{13} \mathrm{C}$ NMR spectra are reported in $\mathrm{ppm}$ downfield ( $\delta$ ) from $\mathrm{Me}_{4} \mathrm{Si}$.

$N$-[(S)-1-phenylethyl]- $N$-(2-propenyl)-2,2,2-

${ }_{45}$ trichloroacetamide 6

To a solution of $N$-[(S)-1-phenylethyl]allylamine ${ }^{12}$ (470 mg, $2.92 \mathrm{mmol})$ in $\mathrm{CH}_{2} \mathrm{Cl}_{2}(15 \mathrm{~mL})$ was added triethylamine $(0.81$ $\mathrm{mL}, 5.84 \mathrm{mmol})$ and the solution was cooled at $0{ }^{\circ} \mathrm{C}$. Trichloroacetyl chloride $(0.49 \mathrm{~mL}, 4.38 \mathrm{mmol})$ in $\mathrm{CH}_{2} \mathrm{Cl}_{2}(1.5$ $50 \mathrm{~mL}$ ) was added and the resulting mixture was heated at reflux for $24 \mathrm{~h}$. The reaction mixture was concentrated, and the resulting residue was dissolved in $\mathrm{CH}_{2} \mathrm{Cl}_{2}$, washed with $1 \mathrm{~N}$ aqueous $\mathrm{HCl}$, and saturated aqueous $\mathrm{Na}_{2} \mathrm{CO}_{3}$. The organic layer was dried, concentrated, and purified by 55 chromatography (10\% EtOAc-hexane) to give 6 (643 mg,
$72 \%)$ as a yellow oil: IR $(\mathrm{NaCl}) 1668(\mathrm{CO}) ;{ }^{1} \mathrm{H}$ NMR $(300$ $\left.\mathrm{MHz}, 50{ }^{\circ} \mathrm{C}\right) 1.74(\mathrm{~d}, J=7 \mathrm{~Hz}, 3 \mathrm{H}), 3.51$ and $4.12(2 \mathrm{br} \mathrm{s}, 2$ $\mathrm{H})$, 5.04-5.14 (m, $2 \mathrm{H})$, 5.74-5.90 (m, $2 \mathrm{H})$, 7.20-7.40 (m, 5 $\mathrm{H}) ;{ }^{13} \mathrm{C}$ NMR (75 MHz, DEPT) $17.7\left(\mathrm{CH}_{3}\right), 48.6(\mathrm{C}-1), 56.8$ $60(\mathrm{CH}), 93.4\left(\mathrm{CCl}_{3}\right), 117.1(\mathrm{C}-3), 126.5,127.5,128.4(\mathrm{C}-o, \mathrm{C}-$ $m, \mathrm{C}-p$ ), 132.5 (C-2), 138.8 (C-ipso), 159.9 (CO). Anal. Calcd for $\mathrm{C}_{13} \mathrm{H}_{14} \mathrm{Cl}_{3} \mathrm{NO}$ : C, 50.92; H, 4.60; N, 4.57. Found: C, 50.77; $\mathrm{H}, 4.65 ; \mathrm{N}, 4.45$.

\section{${ }_{65} N$-(2-Butenyl)- $N$-[(S)-1-phenylethyl]-2,2,2- trichloroacetamide 7}

Similarly, from $N$-(2-Butenyl)- $N$-[(S)-1-phenylethyl $]$ amine $^{13}$ (284 mg, $1.63 \mathrm{mmol}$ ) and after chromatography (hexaned/EtOAc, 9:1) trichloroacetamide 7 (489 mg, 94\%) 70 was isolated as a yellow oil. All spectroscopic data were in accordance with those previously reported. ${ }^{10} \mathrm{IR}(\mathrm{NaCl}): 1670$; ${ }^{1} \mathrm{H}$ NMR (300 MHz) $1.60\left(\mathrm{~d}, J=7 \mathrm{~Hz}, 3 \mathrm{H}, \mathrm{CH}_{3}\right), 2.22(\mathrm{~m}, 2 \mathrm{H}$, $\left.\mathrm{CH}_{2}\right), 2.74$ and $3.25\left(2 \mathrm{~m}, 1 \mathrm{H}\right.$ each, $\left.\mathrm{CH}_{2}\right), 4.82\left(\mathrm{~m}, 2 \mathrm{H}, \mathrm{CH}_{2}\right)$, $5.48(\mathrm{~m}, 1 \mathrm{H}, \mathrm{CH}), 5.73(\mathrm{~m}, 1 \mathrm{H}, \mathrm{CH}), 7.20-7.40(\mathrm{~m}, 5 \mathrm{H}) ;{ }^{13} \mathrm{C}$ $75 \mathrm{NMR}(75 \mathrm{MHz}, \mathrm{DEPT}) 17.9\left(\mathrm{CH}_{3}\right), 32.3(\mathrm{C}-2), 46.4(\mathrm{C}-1)$, $56.8(\mathrm{CH}), 94.2\left(\mathrm{CCl}_{3}\right), 117.0(\mathrm{C}-4), 127.0,127.7,128.6(\mathrm{C}-o$, C-m, C-p), 135.2 (C-3), 139.0 (C-ipso), 160.2 (CO). HRMS (ESI-TOF): calcd for $\mathrm{C}_{14} \mathrm{H}_{17} \mathrm{Cl}_{3} \mathrm{NO} 320.0370\left(\mathrm{M}^{+}+1\right)$; found 320.0374

80

\section{$N$-(3-oxopropyl)- $N$-[(S)-1-phenylethyl $]-2,2,2-$} trichloroacetamide 8

A stirred solution of 7 (1.88 g, $5.87 \mathrm{mmol})$ in $\mathrm{CH}_{2} \mathrm{Cl}_{2}(19.4$ $\mathrm{mL})$ at $-78{ }^{\circ} \mathrm{C}$ was charged with a constant stream of ozone. ${ }_{85}$ After $15 \mathrm{~min}$, the solution was purged with Ar until it was clear and then $\mathrm{Me}_{2} \mathrm{~S}(11.6 \mathrm{~mL}, 158 \mathrm{mmol})$ was added. The reaction mixture was left at $\mathrm{rt}$ for $48 \mathrm{~h}$. It was diluted with $\mathrm{CH}_{2} \mathrm{Cl}_{2}(50 \mathrm{~mL})$, washed with brine, dried and concentrated. Purification of the residue by chromatography $(20 \%$ ${ }_{90} \mathrm{EtOAc/hexane)}$ gave aldehyde $8(1.37 \mathrm{~g}, 73 \%)$ as a clear oil: IR (NaCl): 1670, 1724; ${ }^{1} \mathrm{H}$ NMR (400 MHz) $1.74(\mathrm{~d}, J=6.9$ $\left.\mathrm{Hz}, 3 \mathrm{H}, \mathrm{CH}_{3}\right), 2.50-2.76\left(\mathrm{~m}, 2 \mathrm{H}, \mathrm{CH}_{2}\right), 3.24-3.40(\mathrm{~m}, 1 \mathrm{H}$, $\mathrm{NCH}), 3.48-3.64(\mathrm{~m}, 1 \mathrm{H}, \mathrm{NCH}), 5.82-5.94(\mathrm{q}, J=6.9 \mathrm{~Hz}, 1 \mathrm{H}$, $\mathrm{CH}), 7.30-7.50(\mathrm{~m}, 5 \mathrm{H}, \mathrm{ArH}), 9.63(\mathrm{~s}, 1 \mathrm{H}, \mathrm{CHO}) ;{ }^{13} \mathrm{C} \mathrm{NMR}$ $95\left(100 \mathrm{MHz}\right.$, DEPT) 17,3 $\left(\mathrm{CH}_{3}\right), 39.9\left(\mathrm{CH}_{2}\right), 42.3\left(\mathrm{NCH}_{2}\right), 56.8$ $(\mathrm{CH}), 126.8,128.0$ and 128.7 (C-o, C-m, C-p), 138.3 (C-ipso), 160.4 (CO), 199.5 (CO). Anal. Calcd. for $\mathrm{C}_{13} \mathrm{H}_{14} \mathrm{Cl}_{3} \mathrm{NO}_{2}$ : C, 48,40; H, 4,37; N, 4,34. Found: C, 48,27; H, 4,34; N, 4,27.

\section{$100 \mathrm{~N}$-(3-Acetoxyprop-2-enyl)- $\mathrm{N}$-[(S)-1-phenylethyl]-2,2,2- trichloroacetamide 9}

To a solution of $p$-toluenesulfonic acid monohydrate $(6 \mathrm{mg}$, $0.032 \mathrm{mmol})$ in isopropenyl acetate $(1.5 \mathrm{~mL})$ warmed at reflux temperature was added a solution of aldehyde 8 (103 mg, 0.32 $105 \mathrm{mmol})$ in isopropenyl acetate $(3 \mathrm{~mL})$ and the mixture was stirred for $24 \mathrm{~h}$. To the cooled reaction mixture was added $\mathrm{Et}_{2} \mathrm{O}(10 \mathrm{~mL})$ and the solution was washed with $5 \%$ aqueous $\mathrm{NaHCO}_{3}$ and $\mathrm{H}_{2} \mathrm{O}$. The aqueous extracts were extracted with EtOAc, and the combined organic layers were dried, and 110 concentrated. Purification of the residue by chromatography (Florisil $^{\mathrm{TM}}$, 5\% EtOAc-hexane) gave enol acetate $9(80 \mathrm{mg}$, $68 \%)$ as a yellow oil and as $E: Z$ isomeric mixture (6:4 
according to $\left.{ }^{1} \mathrm{H}-\mathrm{NMR}\right)$ : IR (NaCl) 1760, 1674; ${ }^{1} \mathrm{H}$ NMR (400 $\mathrm{MHz}) 1.74$ (br s, 3H, $\mathrm{CH}_{3}$ ), 2.05, 2.10 (2 s, 3H, $\mathrm{CH}_{3} \mathrm{CO}$ ), 3.40-3.55 and 3.85-4.00 ( $2 \mathrm{~m}, 1.2 \mathrm{H}, E$ isomer, $\left.\mathrm{CH}_{2} \mathrm{~N}\right), 3.60-$ 3.75 and $4.00-4.10\left(2 \mathrm{~m}, 0.8 \mathrm{H}, Z\right.$ isomer, $\left.\mathrm{CH}_{2} \mathrm{~N}\right), 5.00(\mathrm{~m}$, ${ }_{5} 0.4 \mathrm{H}, \mathrm{Z}$ isomer, $\left.\mathrm{CH}=\right), 5.40-5.50(\mathrm{~m}, 0.6 \mathrm{H}, E$ isomer, $\mathrm{CH}=)$, 5.80-6.00 (m, 1H, CH), $7.01(\mathrm{dt}, J=6.3,1.2 \mathrm{~Hz}, 0.4 \mathrm{H}, Z$ isomer, $\mathrm{OCH}=), 7.08(\mathrm{dm}, J=12.9 \mathrm{~Hz}, 0.6 \mathrm{H}, E$ isomer, $\mathrm{OCH}=), 7.20-7.40(\mathrm{~m}, 5 \mathrm{H}, \mathrm{ArH}) ;{ }^{13} \mathrm{C} \mathrm{NMR}(100 \mathrm{MHz}, \mathrm{DEPT})$ 17.4, $17.9\left(\mathrm{CH}_{3}\right), 20.6\left(\mathrm{CH}_{3} \mathrm{CO}\right), 41.1\left(\mathrm{CH}_{2} \mathrm{~N}, \mathrm{Z}\right.$ isomer $), 44.0$ ${ }_{10}\left(\mathrm{CH}_{2} \mathrm{~N}, E\right.$ isomer $), 56.9(\mathrm{CH}), 108.4(\mathrm{CH}=, Z$ isomer $), 108.8$ $(\mathrm{CH}=, E$ isomer), 126.9, 127.7, 127.8, 128.6 (C-o, C- $m, \mathrm{C}-p)$, 135.1 (=CHO), 138.6, 139.0 (=CHO), 160.1 (CO), 167.1, 167.5 (CO). Anal. Calcd for $\mathrm{C}_{15} \mathrm{H}_{16} \mathrm{Cl}_{3} \mathrm{NO}_{3}$ : C, 49.41; $\mathrm{H}, 4.42$; N, 3.84. Found: C, 49,24; H, 4.48; N, 3.69.

(4R)- and (4S)-4-Methyl-1-[(S)-1-phenylethyl]pyrrolidin-2one 10

A suspension of 6 (201 mg, $0.66 \mathrm{mmol})$ and AIBN (115 mg, $0.70 \mathrm{mmol})$ in benzene $(6 \mathrm{~mL})$ was heated to reflux. Then, 20 TTMSS $(0.71 \mathrm{~mL}, 2.30 \mathrm{mmol})$ was added dropwise and the reaction mixture was stirred at this temperature for $2 \mathrm{~h}$ and concentrated. Purification of the residue by chromatography $\left(\mathrm{CH}_{2} \mathrm{Cl}_{2}\right)$ gave $10(106 \mathrm{mg}, 80 \%)$ as a yellow oil and as epimeric mixture (1:1 ratio by $\left.{ }^{1} \mathrm{H}-\mathrm{RMN}\right)$ All spectroscopic 25 data were in accordance with those previously reported. ${ }^{14}$ IR (NaCl) 1670; ${ }^{1} \mathrm{H}$ NMR (300 MHz) 0.97 and $1.10(2 \mathrm{~d}, J=7$ $\left.\mathrm{Hz}, 3 \mathrm{H}, \mathrm{CH}_{3}\right), 1.50$ (d, $\left.J=7 \mathrm{~Hz}, 3 \mathrm{H}, \mathrm{CH}_{3}\right), 2.00$ (dd, $J=16.5$, $6.3 \mathrm{~Hz}, 0.5 \mathrm{H}$ ), $2.05(\mathrm{dd}, J=16.5,7.2 \mathrm{~Hz}, 0.5 \mathrm{H}) 2.20-2.40$ $(\mathrm{m}, 1 \mathrm{H}), 2.50-2.60(\mathrm{~m}, 1.5 \mathrm{H}), 2.85(\mathrm{dd}, J=9.4$ and $6.4 \mathrm{~Hz}$, $\left.{ }_{30} 0.5 \mathrm{H}\right), 3.10(\mathrm{dd}, J=9.4$ and $7.6 \mathrm{~Hz}, 0.5 \mathrm{H}), 3.40(\mathrm{dd}, J=9.3$ and $7.5 \mathrm{~Hz}, 0.5 \mathrm{H}), 5.50(\mathrm{q}, J=7 \mathrm{~Hz}, \mathrm{CH}), 7.25-7.40(\mathrm{~m}, 5 \mathrm{H})$; ${ }^{13} \mathrm{C}$ NMR (75 MHz, DEPT) $16.6\left(\mathrm{CH}_{3}\right), 20.0\left(\mathrm{CH}_{3}\right), 26.8,27.1$ (C-4), 40.3 (C-3), $49.2(\mathrm{CH}), 49.9,50.3$ (C-5), 127.5, 127.9, 128.9 (C-o, C-m, C-p), 140.8.0 (C-ipso), 174.4 (CO). HRMS 35 (ESI-TOF): calcd for $\mathrm{C}_{13} \mathrm{H}_{18} \mathrm{NO} 204.1383\left(\mathrm{M}^{+}+1\right)$ : found 204.1388 .

(4R)- and (4S)-1-[(S)-1-Phenylethyl]-4-methylpiperidin-2one 11

40 Similarly, trichloroacetamide $7(290 \mathrm{mg}, 0.91 \mathrm{mmol})$ in benzene $(8.7 \mathrm{~mL})$ was treated with AIBN (164 mg, 1.00 mmol) and TTMSS $(0.98 \mathrm{~mL}, 3.17 \mathrm{mmol})$, and the crude material was purified by chromatography (EtOAc) to give 6 $(105 \mathrm{mg}, 53 \%)$ as a yellow oil and as epimeric mixture (1:1 45 ratio by $\left.{ }^{1} \mathrm{H}-\mathrm{RMN}\right)$ : IR $(\mathrm{NaCl}) 1634 ;{ }^{1} \mathrm{H}$ NMR $(400 \mathrm{MHz})$ 0.95, $0.97\left(2 \mathrm{~d}, J=2.4 \mathrm{~Hz}, 3 \mathrm{H}, \mathrm{CH}_{3}\right), 1,24(\mathrm{dtd}, J=13.6,10.4$, $\left.5.6 \mathrm{~Hz}, 0.5 \mathrm{H}, \mathrm{H}-5_{\mathrm{ax}}\right), 1.49$ and $1.50(2 \mathrm{~d}, J=6.9 \mathrm{~Hz}, 3 \mathrm{H}$, $\left.\mathrm{CH}_{3}\right), 1.75\left(\mathrm{dm}, J=13.2 \mathrm{~Hz}, 0.5 \mathrm{H}, \mathrm{H}-5_{\mathrm{eq}}\right), 1,80-2,00(\mathrm{~m}, 1 \mathrm{H}$, H-4), 2.06 (dd, $J=17.2,3.6 \mathrm{~Hz}, 0.5 \mathrm{H}, \mathrm{H}-3), 2.08(\mathrm{dd}, J=$ $5017.2,4.4 \mathrm{~Hz}, 0.5 \mathrm{H}, \mathrm{H}-3), 2.56(\mathrm{td}, J=5.2,2 \mathrm{~Hz}, 0.5 \mathrm{H}, \mathrm{H}-3)$, $2.61(\mathrm{td}, J=5.3,2 \mathrm{~Hz}, 0.5 \mathrm{H}, \mathrm{H}-3), 2,66(\mathrm{ddd}, J=12.5,10.5$, $\left.4.6 \mathrm{~Hz}, 0.5 \mathrm{H}, \mathrm{H}-6_{\mathrm{ax}}\right), 2.86(\mathrm{ddd}, J=12.1,4.8,3.4 \mathrm{~Hz}, 0.5 \mathrm{H}$, H-6 eq ), 3,07-3,16 (m, 1H, H-6), 6,14 (q, $J=7 \mathrm{~Hz}, 1 \mathrm{H}, \mathrm{CH})$, 7.20-7.40 (m, 5H, ArH); ${ }^{13} \mathrm{C}$ NMR (100 MHz, DEPT) 15.0, $5515.3\left(\mathrm{CH}_{3}\right), 20.8,21.1\left(\mathrm{CH}_{3}\right), 27.3,27.8(\mathrm{C}-4), 30.7,30.8(\mathrm{C}-$ 5), 40.2, 40.4, 40.5, 40.60 (C-3 and C-6), 49.3, $49.4(\mathrm{CH})$, 126.9, 127.0, 127.3, 128.2 (C-o, C-m, C-p), 140.0, 140.5 (Cipso), 169.1, 169.2 (C-2). Anal. Calcd for $\mathrm{C}_{14} \mathrm{H}_{19} \mathrm{NO}$ : C,
77.38; H, 8.81; N, 6.45. Found: C, 77.21; H, 8.84; N, 6.40. 60

(4R)- and (4S)-4-Acetoxymethyl-1-[(S)-1phenylethyl]pyrrolidin-2-one 12

Following the above procedure for the cyclization of $\mathbf{6}$ to $\mathbf{1 0}$, from trichloroacetamide $9(282 \mathrm{mg}, 0.77 \mathrm{mmol})$ with a $3 \mathrm{~h}$ of 65 reaction time, pyrrolidone $\mathbf{1 2 a}(78 \mathrm{mg})$ and its epimer $\mathbf{1 2 b}$ (79 $\mathrm{mg}$ ) were obtained after chromatography (EtOAc) as yellow oils (78\% overall yield). 12a: IR $(\mathrm{NaCl}) 1741,1684 ;{ }^{1} \mathrm{H}$ NMR $(400 \mathrm{MHz}) 1.52\left(\mathrm{~d}, J=6.8 \mathrm{~Hz}, 3 \mathrm{H}, \mathrm{CH}_{3}\right), 2,05(\mathrm{~s}, 3 \mathrm{H}$, $\mathrm{CH}_{3} \mathrm{CO}$ ), 2.26 (dd, $\left.J=20.4,10 \mathrm{~Hz}, 1 \mathrm{H}, \mathrm{H}-3\right), 2.58$ (dd, $J=$ $7019.8,8.4 \mathrm{~Hz}, 1 \mathrm{H}, \mathrm{H}-3), 2.56-2.62(\mathrm{~m}, 1 \mathrm{H}, \mathrm{H}-4), 3.09$ (d, $J=6$ $\mathrm{Hz}, 2 \mathrm{H}, \mathrm{H}-5), 4.02$ (dd, J= 11.4, $6.8 \mathrm{~Hz}, 1 \mathrm{H}, \mathrm{CHO}$ ), 4.08 (dd, $J=11.2,5.6 \mathrm{~Hz}, 1 \mathrm{H}, \mathrm{CHO}), 5.50$ (q, $J=7.2 \mathrm{~Hz}, 1 \mathrm{H}, \mathrm{CH})$, 7.20-7.40 (m, 5H, ArH); ${ }^{13} \mathrm{C}$ NMR (100 MHz, DEPT) 16.0 $\left(\mathrm{CH}_{3}\right), 20.7\left(\mathrm{CH}_{3} \mathrm{CO}\right), 30.4(\mathrm{C}-4), 34.4(\mathrm{C}-3), 44.8$ (C-5), 48.9 $75(\mathrm{CH}), 65.9\left(\mathrm{CH}_{2} \mathrm{O}\right), 127.0,127.5$ and $128.5(\mathrm{C}-o, \mathrm{C}-m, \mathrm{C}-p)$, 139.8 (C-ipso), 170.8 (CO), 172.7 (CO). Anal. Calcd. for $\mathrm{C}_{15} \mathrm{H}_{19} \mathrm{NO}_{3} \cdot 1 / 10 \mathrm{H}_{2} \mathrm{O}: \mathrm{C}, 68.47 ; \mathrm{H}, 7.35 ; \mathrm{N}, 5.32$. Found: $\mathrm{C}$, 68.30; H, 7.55; N, 5.37. 12b: IR ( NaCl): 1740, 1683; ${ }^{1} \mathrm{H}$ NMR $(400 \mathrm{MHz}) 1.53\left(\mathrm{~d}, J=7.2 \mathrm{~Hz}, 3 \mathrm{H}, \mathrm{CH}_{3}\right), 1.97(\mathrm{~s}, 3 \mathrm{H}$, ${ }_{80} \mathrm{COCH}_{3}$ ), 2.23 (ddd, $J=19.6,10,4.2 \mathrm{~Hz}, 1 \mathrm{H}, \mathrm{H}-3$ ), 2.53-2.67 (m, 2H, H-3, H-4), 2.74 (dd, $J=10,4.8 \mathrm{~Hz}, 1 \mathrm{H}, \mathrm{H}-5), 3.45$ $(\mathrm{dd}, J=10,7.6 \mathrm{~Hz}, 1 \mathrm{H}, \mathrm{H}-5), 3.87$ (dd, $J=10.8,6.8 \mathrm{~Hz}, 1 \mathrm{H}$, CHO), 3.94 (dd, $J=10,6,6 \mathrm{~Hz}, 1 \mathrm{H}, \mathrm{CHO}), 5.50$ (q, $J=7.2$ $\mathrm{Hz}, 1 \mathrm{H}, \mathrm{CH}), 7.20-7.40$ (m, 5H, ArH); ${ }^{13} \mathrm{C} \mathrm{NMR}(100 \mathrm{MHz}$, ${ }_{85}$ DEPT) $16.0\left(\mathrm{CH}_{3}\right), 20.6\left(\mathrm{CH}_{3} \mathrm{CO}\right), 30.1(\mathrm{C}-4), 34.5(\mathrm{C}-3)$, $44.9(\mathrm{C}-5), 49.0(\mathrm{CH}), 65.8\left(\mathrm{CH}_{2} \mathrm{O}\right), 127.0,127.6$ and 128.5 (C-o, C-m, C-p), 139.8 (C-ipso), 170.7 (CO), 172.8 (CO). Anal. Calcd. for $\mathrm{C}_{15} \mathrm{H}_{19} \mathrm{NO}_{3} \cdot 1 / 2 \mathrm{H}_{2} \mathrm{O}$ : C, 66.64; H, 7.46; N, 5.18. Found: C, 66.64; H, 7.37; N, 5.18.

90

\section{Computational methods}

All calculations were carried out with the Gaussian 03 suite of programs. ${ }^{15}$ Density functional theory ${ }^{16}$ calculations (DFT) have carried out using the $\mathrm{B} 3 \mathrm{LYP}^{17}$ exchange-correlation ${ }_{95}$ functionals, together with the standard $6-31 \mathrm{G}^{* *}$ basis set. ${ }^{18}$ The stationary points were characterized by frequency calculations in order to verify that minima and transition structures have zero and one imaginary frequency, respectively. The inclusion of solvent effects have been 100 considered by using a relatively simple self-consistent reaction field (SCRF) method ${ }^{19}$ based on the polarizable continuum model (PCM) of Tomasi's group. ${ }^{20}$ As solvent we have used benzene. Gaussian treats $\mathrm{H}$ atoms as part of a fragment $(\mathrm{OH}, \mathrm{CH}, \mathrm{SH}$ etc) when creating cavities in the PCM 105 model. In some cases (e.g. heavy atom-H bond is elongated), cavity building fails. For this reason, we have used the cavity model that also assigns spheres to hydrogens (radii=uff).

\section{Acknowledgments}

110 This research was supported by the Ministry of Education and Science (Spain)-FEDER through projects CTQ200761338/BQU, CTQ2009-11027/BQU and CTQ2009-13699 and Universidad Politecnica de Valencia (2005-PPI-06-05). 


\section{Notes and references}

1 (a) A. J. Clark, Chem. Soc. Rev., 2002, 31, 1. (b) M. Pattarozzi, F. Roncaglia, V. Giangiordano, P. Davoli, F. Prati and F. Ghelfi, Synthesis 2010, 694. (c) Y. Motoyama, K. Kamo, A. Yuasa and H. Nagashima, Chem. Commun., 2010, 2256.

2 (a) B. A. Seigal, C. Fajardo and M. L. Snapper, J. Am. Chem. Soc., 2005, 127, 16329. (b) C. D. Edlin, J. Faulkner and P. Quayle, Tetrahedron Lett., 2006, 47, 1145. (c) F. I. McGonagle, L. Brown, A. Cooke and A. Sutherland, Org. Biomol. Chem., 2010, 8, 3418.

3 J. Quirante, C. Escolano, A. Merino and J. Bonjoch, J. Org. Chem., 1998, 63, 968.

4 X. Vila, J. Quirante, L. Paloma and J. Bonjoch, Tetrahedron Lett., 2004, 45, 4661.

5 (a) J. Quirante, C. Escolano, M. Massot and J. Bonjoch, Tetrahedron, 1997, 53, 1391. (b) J. Quirante, C. Escolano, F. Diaba and J. Bonjoch, Heterocycles, 1999, 50, 731. (c) J. Quirante, C. Escolano, F. Diaba and J. Bonjoch, J. Chem. Soc., Perkin Trans. 1, 1999, 1157.

6 J. Quirante, M. Torra, F. Diaba, C. Escolano and J. Bonjoch, Tetrahedron: Asymmetry, 1999, 10, 2399.

7 J. Quirante, F. Diaba, X. Vila, J. Bonjoch, E. Lago and E. Molins, C. R. Acad. Sci. Paris, 2001, 4, 513.

8 (a) X. L. Huang and J. J. Dannenberg, J. Org. Chem., 1991, 56, 5421. (b) M. Gulea, J. M. López-Romero, L. Fensterbank and M. Malacria, Org. Lett., 2000, 2, 2591. (c) J. Cassayre and S. Z. Zard, J. Organometal. Chem., 2001, 624, 316.

9 For radical cyclizations involving $N$-( $\alpha$-methylbenzyl) substituted compounds, see: (a) B. Cardillo, R. Galeazzi, G. Mobbili, M. Orena and M. Rossetti, Heterocycles, 1994, 38, 2663. (b) H. Ishibashi, C. Kameoka, K. Kodama and M. Ikeda, Tetrahedron, 1996, 52, 489. (c) H. Ishibashi, Y. Fuke, T. Yamashita and M. Ikeda, Tetrahedron: Asymmetry, 1996, 7, 2531. (d) H. Ishibashi, K. Kodama, C. Kameoka, H. Kawanami and M. Ikeda, Tetrahedron, 1996, 52, 1386. (e) H. Ishibashi, C. Kameoka, K. Kodama, H. Kawanami, M. Humada and M. Okeda, Tetrahedron, 1997, 53, 9611. (f) M. Ikeda, S. Ohtani, T. Sato and H. Ishibashi, Synthesis, 1998, 1803.

10 A. J. Clark, F. De Campo, R. J. Deeth, R. P. Filik, S. Gatard, N. A. Hunt, D. Lastécouères, G. H. Thomas, J.-B. Verlhac and H. Wongtap, J. Chem. Soc. Perkin 1, 2000, 671.

11 R. I. Duclos Jr. and A. Makriyannis, J. Org. Chem., 1992, 57, 6156.

12 (a) G. Cardillo, M. Orena, M. Penna, S. Sandri and C. Tomasini, Tetrahedron, 1991, 47, 2263. (b) B. Cardillo, R. Galeazzi, G. Mobbili, M. Orena and M. Rossetti, Tetrahedron: Asymmetry, 1996, 7, 3573. (c) M. Yus, F. Foubelo and L. R. Falvello, Tetrahedron: Asymmetry, 1995, 6, 2081. (d) V. Rodríguez, M. Sánchez, L. Quintero and F. Sartillo-Piscil, Tetrahedron, 2004, 60, 10809.
13 P. Karoyan and G. Chassaing, Tetrahedron: Asymmetry, 1997, 8, 2025.

14 For alternative radical procedures leading to $\mathbf{1 0}$ and their analytical data, see: (a) M. Ikeda, H. Teranishi, K. Nozaki and H. Ishibashi, $J$. Chem. Soc., Perkin Trans. 1, 1998, 1691. (b) B. Cardillo, R. Galeazzi, G. Mobbili, M. Orena and M. Rossetti, Heterocycles, 1994, 38, 2663.

15 M. J. Frisch, G. W. Trucks, H. B. Schlegel, G. E. Scuseria, M. A. Robb, J. R. Cheeseman, J. A. Montgomery Jr., T. Vreven, K. N. Kudin, J. C. Burant, J. M. Millam, S. S. Iyengar, J. Tomasi, V. Barone, B. Mennucci, M. Cossi, G. Scalmani, N. Rega, G. A. Petersson, H. Nakatsuji, M. Hada, M. Ehara, K. Toyota, R. Fukuda, J. Hasegawa, M. Ishida, T. Nakajima, Y. Honda, O. Kitao, H. Nakai, M. Klene, X. Li, J. E. Knox, H .P. Hratchian, J. B. Cross, C. Adamo, J. Jaramillo, R. Gomperts, R. E. Stratmann, O. Yazyev, A. J. Austin, R. Cammi, C. Pomelli, J. W. Ochterski, P. Y. Ayala, K. Morokuma, G. A. Voth, P. Salvador, J. J. Dannenberg, V. G. Zakrzewski, S. Dapprich, A. D. Daniels, M. C. Strain, O. Farkas, D. K. Malick, A. D. Rabuck, K. Raghavachari, J. B. Foresman, J. V. Ortiz, Q. Cui, A. G. Baboul, S. Clifford, J. Cioslowski, B. B. Stefanov, G. Liu, A. Liashenko, P. Piskorz, I. Komaromi, R. L. Martin, D. J. Fox, T. Keith, M. A. Al-Laham, C. Y. Peng, A. Nanayakkara, M. Challacombe, P. M. W. Gill, B. Johnson, W. Chen, M. W. Wong, C. Gonzalez and J. A. Pople, Gaussian 03, Revision C. 02, Gaussian, Inc.: Wallingford CT, 2004.

16 (a) R. G. Parr and W. Yang, Density Functional Theory of Atoms and Molecules; Oxford University Press: New York, 1989. (b) T. Ziegler, Chem. Rev., 1991, 91, 651.

17 (a) A. D. Becke, J. Chem. Phys., 1993, 98, 5648. (b) C. Lee, W. Yang and R. G. Parr, Phys. Rev. B, 1988, 37, 785.

18 W. J. Hehre, L. Radom, P. V. R. Schleyer and J. A. Pople, Ab initio Molecular Orbital Theory; Wiley: New York, 1986.

19 (a) J. Tomasi and M. Persico, Chem. Rev., 1994, 94, 2027. (b) B. Y. Simkin and I. Sheikhet, Quantum Chemical and Statistical Theory of Solutions-A Computational Approach; Ellis Horwood: London, 1995.

20 (a) E. Cances, B. Mennunci and J. Tomasi, J. Chem. Phys., 1997, 107, 3032. (b) M. Cossi, V. Barone, R. Cammi and J. Tomasi, Chem. Phys. Lett., 1996, 255, 327. (c) V. Barone, M. Cossi and J. Tomasi, J. Comp. Chem., 1998, 19, 404. 